\title{
Syncytial Cell Surface of Placental Villi Associate with Obesity
}

\author{
Olivar C Castejon S1* and Angela J Lopez G1 \\ ${ }^{1}$ Faculty of Health Sciences, University of Carabobo-Aragua Nucleus, Venezuela
}

*Corresponding author: Olivar C Castejon, Holder in Cell Biology, Director of CIADANA, Electron Microscopy Laboratory, Faculty of Health Sciences, University of CaraboboAragua Nucleus, Aragua State, Maracay, Venezuela, Tel: 0243-2713305; Ext. 102; Fax:

\section{Case Report \\ Volume 3 Issue 2}

Received Date: July 02, 2018

Published Date: July 24, 2018

DOI: $10.23880 /$ cclsj-16000128

0243-2713312; Email: olivar.ciadanauc@gmail.com

\section{Abstract}

In this work to describe the observations of syncytial cell surface in placental villi, in obese woman pregnancy of 92Kg, not associated to hypertension, with gain of $9 \mathrm{Kg}$ of weight during pregnancy has been the objective. The placenta was analyzed according to previous data obtained with light and scanning electron microscopy. Mature intermediate villi were seen with a diameter under the average normal diameter from 60 to $150 \mathrm{um}$ as indicated in the literature. They showed wrinkled cell surface, without bends in its longitudinal axis and scarcity of terminal villi. These also presented an average diameter minor when compared to the normal range of 30 -80um.In immature intermediate villi globular extensions as blebs were seen collapsed and numerous elevations and depressions were found. In both intermediate villi as well as terminal villi scarcity of irregular microvilli was found. In this case not overgrowth in newborn was seen since the gestational weight gain correspond with their body mass index indicating that the syncytial placental membrane has regulated the transfer of gases and nutrients for the normal fetal development during obesity.

Keywords: Scanning Electron Microscopy; Placental Villi; Obesity

Abbreviations: SEM: Scanning Electron Microscopy; BMI: Body Mass Index; LPL: Lipo Protein Lipase.

\section{Introduction}

Pregravid obesity is associated with increased morbidity and mortality for both mother and offspring. Changes in placental structure that characterize an inflammatory status in obese women have been found. Immaturity, increased number of capillaries and vascular abnormalities were observed in placental villi of woman obese [1]. Maternal obesity is a frequent obstetric risk factor linked with short and long term consequences for mother and child including fetal overgrowth, growth restriction and stillbirth provoking reduction in placental villous proliferation and reductions in apoptosis which may increase susceptibility to adverse pregnancy outcomes [2].

Placental inflammatory lesions may underlie the worse pregnancy course when compared to normal weight women [3]. These obese women with reduced placental vascularity and blood flow would restrict placental nutrient delivery to the developing fetus [4]. The obese maternal environment is characterized by hyperlipidemia and an exaggerated state of inflammation with oxidative stress and the placenta transduces and mediates the effect of the adverse maternal environment 


\section{Cell \& Cellular Life Sciences Journal}

to the fetus. Heightened inflammation and oxidative stress are found in the placenta [5].

Studies have identified an accumulation of macrophages with enhanced expression of proinflammatory cytokines in placenta of obese women analogous to chronic villitis [6]. The under perfusion of the intervillous space can to result in local areas with increased perivillous fibrin and villous agglutination. Our studies have permitted to observe regions of stromal separated of the syncytio when the obesity is associated with hypertension [7].

Microvilli of the syncytio have been observed reduced in number, and slender and thicker in their extremity are seen with transmission electron microscopy in the baboon $[8,9]$. It has been hypothesized that maternal obesity results in increased placental nutrient transport to the fetus. The extent of lipid transfer to the fetus strongly contributes to fetal fat accretion $[10,11]$.

In this work to amply the observations of syncytial cell surface in placental villi not associated with hypertension in a case of obesity of woman pregnancy of $92 \mathrm{Kg}$ is our objective.

\section{Case Report}

A placenta was obtained of woman pregnancy of 20 years old and $101 \mathrm{Kg}$ of weight, at 39 weeks of gestation, who had an increased weight of $9 \mathrm{~kg}$ during pregnancy and a body mass index (BMI) of 36. The patient without hypertension was informed following basic ethical principles of the declaration of Helsinki as well as the rules of the ethical committee of our institution.

This study is descriptive, retrospective and no experimental with not probabilistic sampling. The observations found in placental villi were selected in two groups: A group study and control group. A protocol of features was applied to these two groups determining structural characteristics of placental villi associated with obesity using Scanning Electron Microscopy (SEM).

Details of the syncytial cell surface of the different types of placental villi were observed and taken with a Hitachi S2300 scanning electron microscope. The nomenclature and classification of the placental villi here described is the mentioned by Benirschke and Kaufmann [12].

\section{Results}

In the groups of placental villi observed in Figures 1-4 the mature intermediate villi have a diameter under the average diameter from 60-150 um [12]. The cell surface of these villi is showed wrinkled and not presentsa uniform distribution of microvilli. In the Figures 5-8 immature intermediate villi are seen with elevations and depressions of the syncytial plasmamembrane,globular extensions as blebs can to be observed and a scarcity and irregular microvilli is noted.Mature intermediate villi when were observed to high resolution showed smooth regions and zones of irregular microvilli (Figure 9). These not present the characteristics bends of its longitudinal axis without terminal villi or with scarcity of these. Terminal villi with frequency are seen in the extremity of mature intermediate villi showing a typical constricted neck region (Figure 10). The average diameter of these villi is minor when compared to the range from 30-80 um [12].

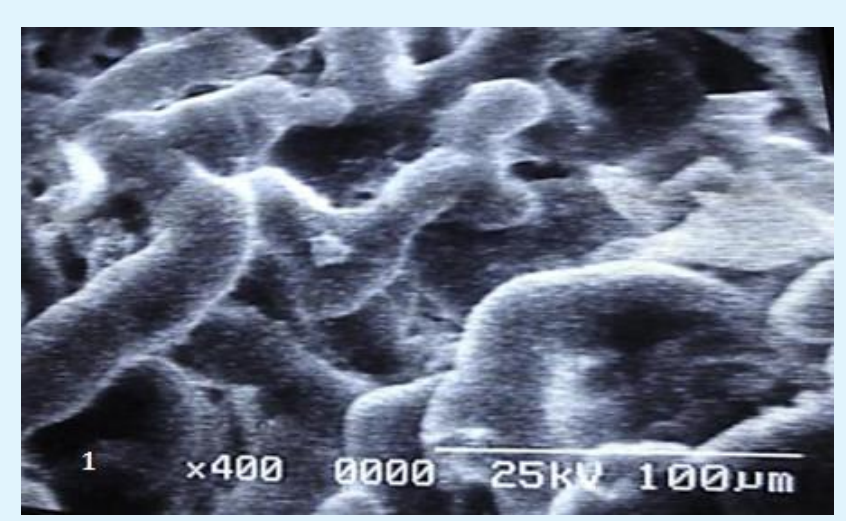

Figure 1: Short ramification of mature intermediate villi is observed with irregular microvilli.

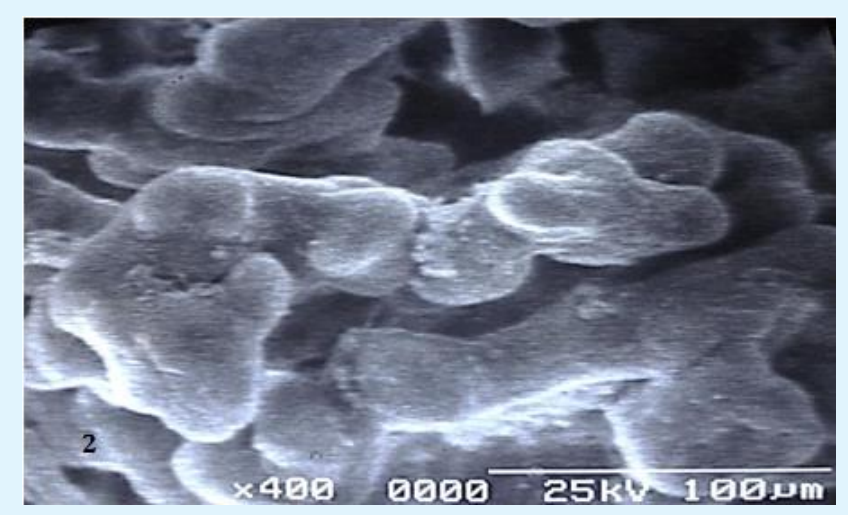

Figure 2: A groups of immature intermediate villi are showing globular extensions of their cell surface. 


\section{Cell \& Cellular Life Sciences Journal}

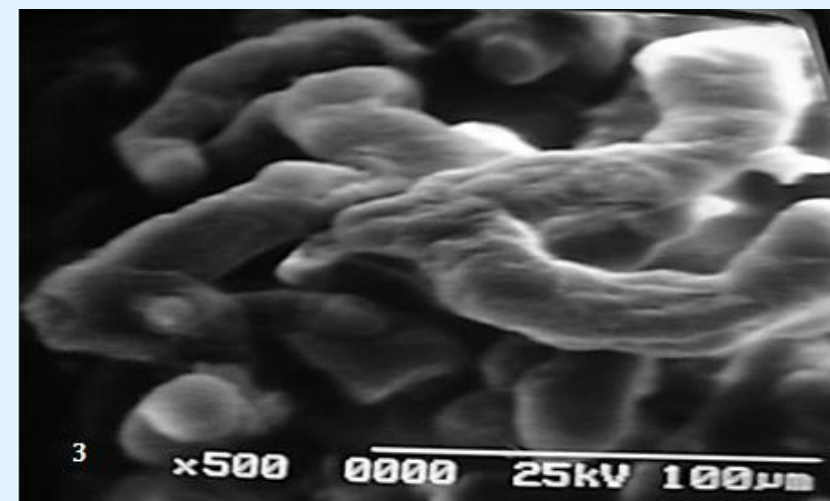

Figure 3: Mature intermediate villi shows a cell surface wrinkled.

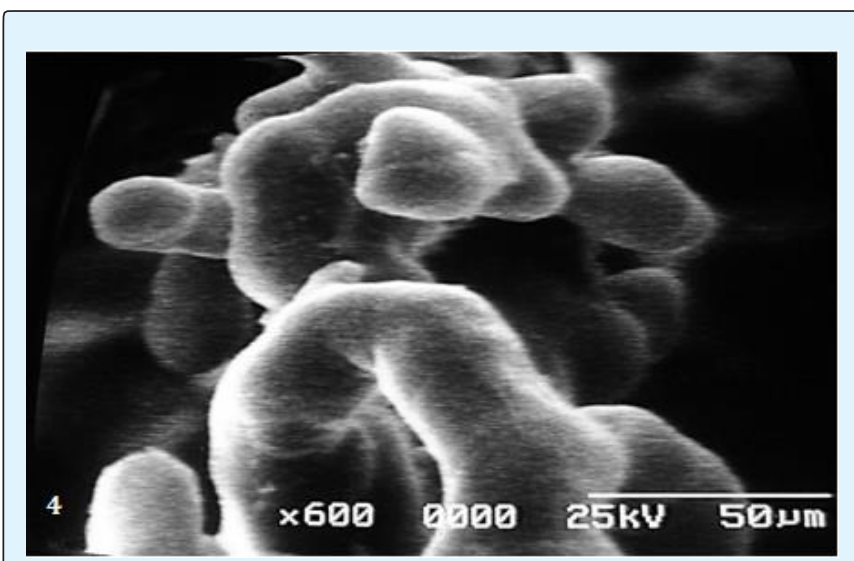

Figure 4: Curved mature intermediate villi are seen near of immature intermediate villi.

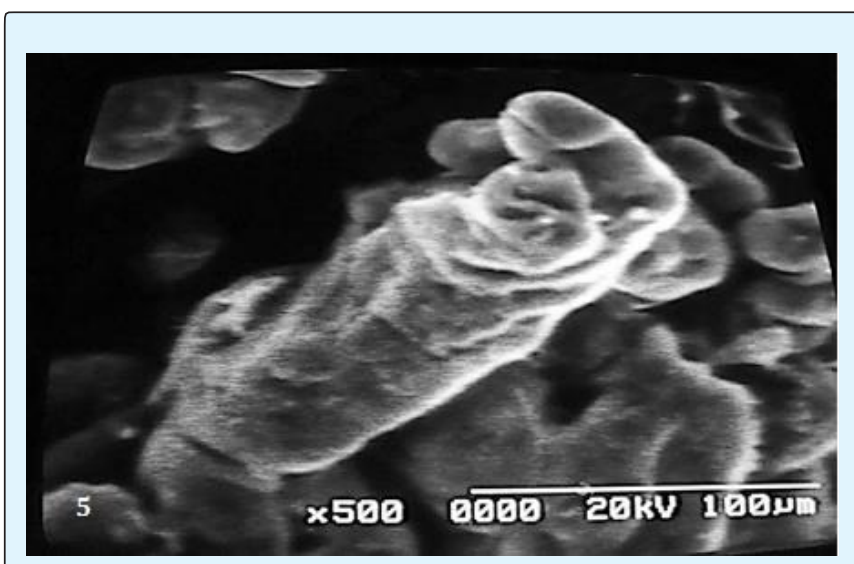

Figure 5: Immature villi exhibits collapsed globular extensions.

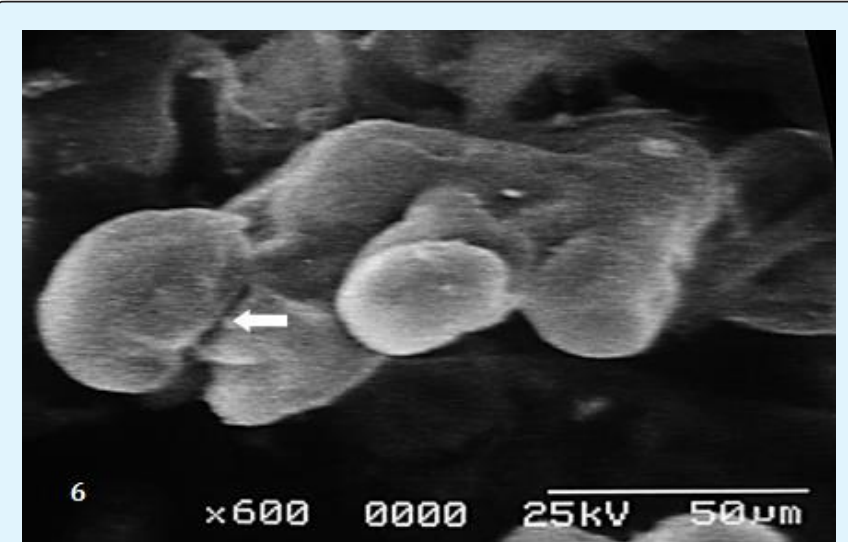

Figure 6: The arrow indicates a fracture of the syncytial membrane in immature villi.

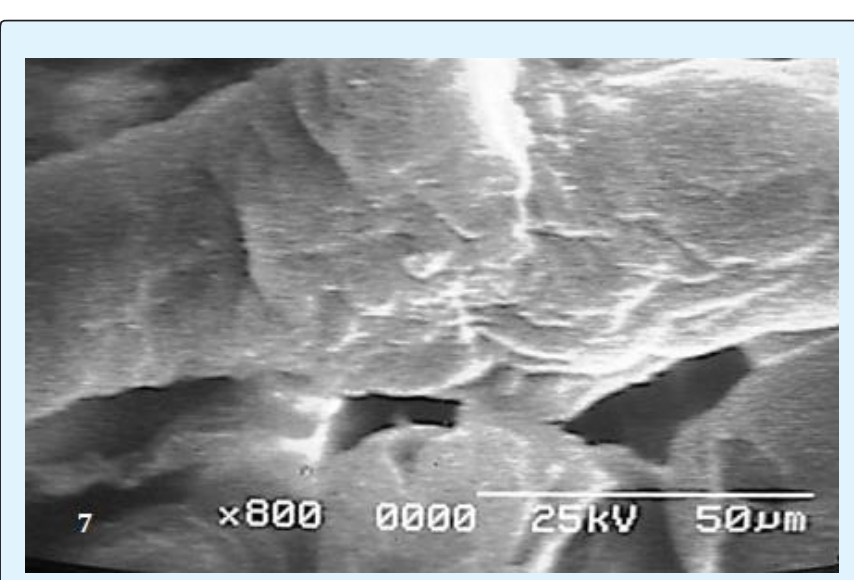

Figure 7: Immature intermediate villi present a scalloped surface.

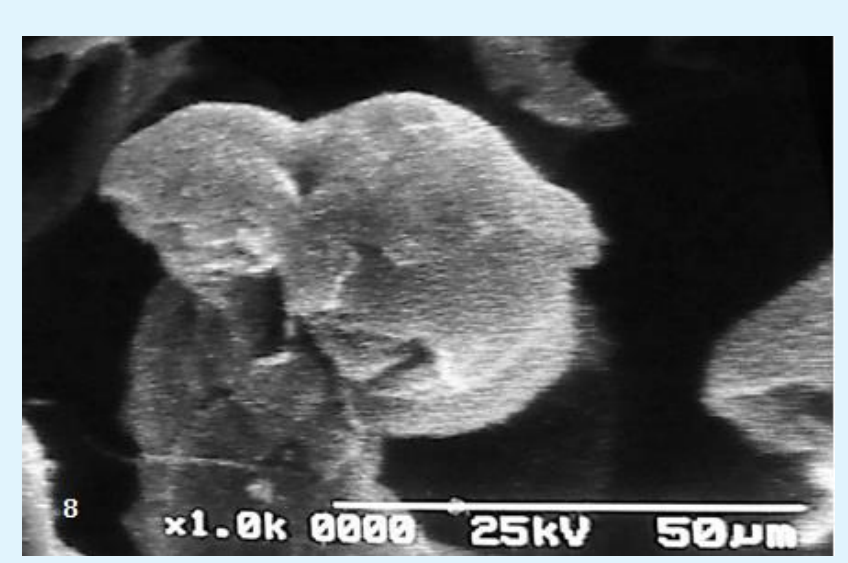

Figure 8: Immature villi show irregular microvilli on the cell surface. 


\section{Cell \& Cellular Life Sciences Journal}

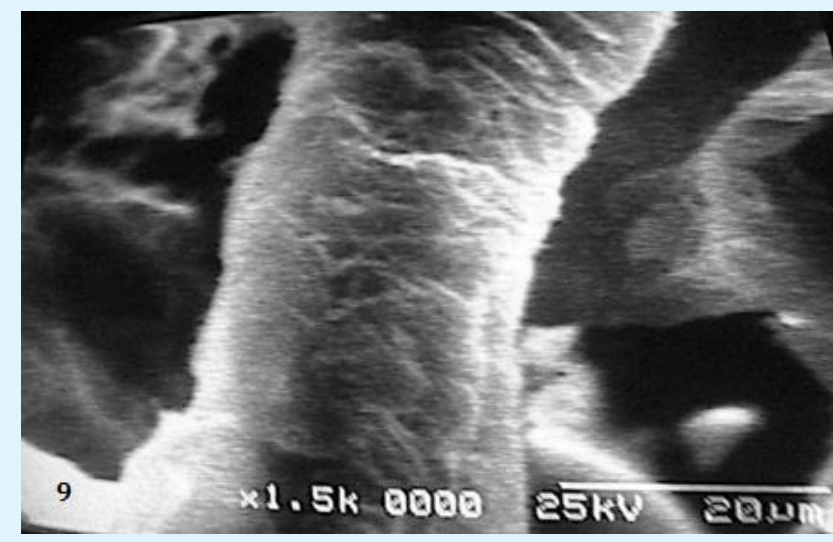

Figure 9: Section of mature villi is seen without uniform distribution of microvilli.

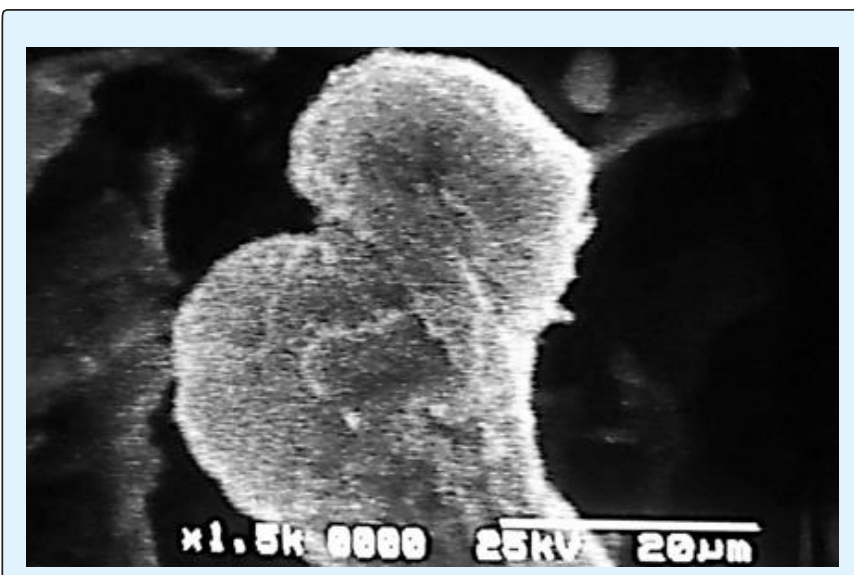

Figure 10: Terminal villi with narrow neck region associate to a part of mature intermediate villi.

\section{Discussion}

It is known that in lipidic metabolism during pregnancy the angiopoietin-like protein 4 (ANGPTL-4) is secreted from adipose tissue and placenta, which inhibits lipoprotein lipase (LPL) activity. So, a greater fatty acid placental was not produced not contributing to the higher fetal fat accumulation [13].

Maternal obesity increases the risk of poor pregnancy outcome associated with dysfunctional syncytiotrophoblast since taurine (a B-amino acid with antioxidant and cytoprotective properties) uptake maintains the syncytial plasma membrane and this uptake is very lower in obese woman. Tiamine is likely to have a critical role facilitating syncytiotrophoblast renewal and cell survival. It regulate their cell volume, and a deficient trophoblast in uptake taurine from maternal blood via the taurine amino-acid transporter on the syncytiotrophoblast microvillous plasma membrane could to increase their susceptibility to inflammatory process [14]. In this condition the transfer of nutrients and gases to the fetus is affected.

It is possible that the delayed fixation after of cord clamping influence on the wrinkled cell surface of the syncytio seen in mature villi during post partal changes and in immature villi with collapsed globular extensions [12].

Globular extensions in immature villi are produced by distended vessels in the stromal region which elevates the syncytio. The fractures observed in the syncytio could to be originated when sudden increment of high blood pressure of the intervillous space provoke the rupture being so obtained the curved form of the villi. In this type of patient the reduced blood flow by atherosis in uteroplacental vessels of the basal plate has produced short villi and very lean. .

When obesity is associated to hypertension numerous microvilli were seen on the cell surface of syncytio in immature intermediate villi with different size and irregular form. The syncytio can to be separated of the stromal region and the reduction of blood flow in the intervillous space results in syncytial damage [7].

Findings of depressed mitochondrial oxygen consumption, reduction in maximum respiration, mitochondrial deficiency or mitochondrial dysfunction at level of the syncytio in maternal obesity could to be affecting the integrity of the plasma membrane [15]. Higher numbers of neutrophils within the interstitial space, greater muscularity of placental vessel walls and cytokines was associated with maternal obesity demonstrating a heightened inflammatory response [16].

We have not found in this increasing maternal body mass index a systemic inflammation in the mother as has been reported by others [17]. Placentas of obese woman had $17.5 \%$ more lipid than placentas of lean woman and maternal obesity may lead to higher supply of nutrients to the fetus-placental unit and to excessive fetal fat accumulation. Animal models show that maternal obesity is associated with carriers resulting in enhanced lipid transfer across the placenta $[18,19]$.

The extent of lipid transfer to the fetus strongly contributes to fetal fat accretion. Human in vivo studies using labeled fatty acids reported a preferential placental- 


\section{Cell \& Cellular Life Sciences Journal}

fetal transfer of long-chain of poly unsaturated fatty although the mechanisms are still uncertain. Knowledge about fatty acids metabolism and adaptations of the placenta in response to obesity are more limited and contradictory results are available in the literature $[20,21]$. Reduced syncytium formation is observed in complicated pregnancies by preeclampsia and intrauterine grow retardation associated with fetal programming of obesity [22].

If well in this report the patient had $101 \mathrm{Kg}$ of weight and a body mass index of 36 , their obesity not provoked grave consequence to the fetal development since the weight of newborn was of $3 \mathrm{Kg}$ and their stature of $52 \mathrm{~cm}$ which correspond with the 39 week of gestation in our tables of measurements fetal/placental ratio of normal pregnancy, with a maternal gestational weight gain of only $9 \mathrm{Kg}$. Although for this index a better maternal gestational weight is $7 \mathrm{Kg}[23,24]$. Actually this maternal gestational weight gain is between 9 and $11 \mathrm{Kg}$ [25].

In conclusion, during pregnancy at term associated with obesity, the plasma membrane of the placental villi regulates the transfer of gases and nutrients to the fetus when maternal gestational weight gain is according to their body mass index.

\section{References}

1. Loardi C, Falchetti M, Prefumo F, Facchetti F, Frusca T (2016) Placental morphology in pregnancies associated with pregravid obesity. J Matern Fet Neonat Med 29(16): 2611-2616.

2. Higgins L, Mills TA, Greewood SL, Cowley EJ, Sibley CP, et al. (2013) Maternal obesity and its effect on placental cell turnover. J Matern Fet Neonat Med 26(8): 783-788.

3. Bar J, Schreiber L, Saruhanov E, Ben HA, Golan A, et al. (2012) Placental histopathological findings in obese and non obese woman with complicated and uncomplicated pregnancies. Arch Gynecol Obstet 286(6): 1343-1347.

4. Howell KR, Power TL (2017) Effects of maternal obesity on placental function and fetal development. Reproduction 153(3): 97-108.

5. Myatt L, Maloyan A (2016) Obesity and placental function. Semin Reprod Med 34(1): 42-49.
6. Challier JC, Basu S, Bintein T, Hotmire K, Minium J, et al. (2008) Obesity in pregnancy stimulates macrophague accumulation and inflammation in the placenta. Placenta 29(3): 274-281.

7. Castejon SOC, Lopez GAJ (2013) A light and scanning electron microscopy study of placental villi associated with obesity and hypertension. Rev Electron Biomed/Electron J Biomed 2: 29-36.

8. Biagini G, Vasi V, Pugnaloni A, Valensise H, Rizzoli R, et al. (1989) Morphological development of the human placenta in normal and complicated gestation: a quantitative and ultra structural study. Gynecol Obstet Invest 28(2): 62-69.

9. Farley D, Tejero ME, Comuzzie AG, Higgins PB, Cox L, et al. (2009) Fetus-placental adaptations to maternal obesity in the baboon. Placenta 30(9): 752-760.

10. Jones HN, Powell TL, Janson T (2007) Regulation of placental nutrient transport-a review. Placenta 28(89): 763-774.

11. Jones HN, Woollett LA, Barbour N, Prasal PD, Powell TL, et al. (2009) High-fat diet before and during pregnancy causes marked up-regulation of placental nutrient transport and fetal overgrowth in C57/BL6 mice. Faseb J 23(1): 271-278.

12. Benirschke K, Kaufmann P (2014) Pathology of the human placenta, $4^{\text {th }}$ (Edn.), New York: Spriger-Verlag.

13. Herrera E, Ortega-Senovilla H (2014) Lipid metabolism during pregnancy and its implications for fetal growth. Curr Pharm Biothechnol 15(1): 24-31.

14. Ditchfield AM, Desforges M, Mills TA, Glazier JD, Wareing $M$, et al. (2015) Maternal obesity is associated with a reduction in placental taurine transporter activity. Int J Obesity (Lond) 39(4): 557 564.

15. Mele J, Muralimancharan S, MaloyanA,Myatt L (2014) Impaired mitochomdrial function in human placenta with increased maternal adiposity. Am J Physiol Endocrinol Metab 307(5): 419-425.

16. Roberts KA, Riley SC, Reynolds RM, Barr S, Evans M, et al. (2011) Placental structure and inflammation in pregnancies associated with obesity. Placenta 32(3): 247-254. 


\section{Cell \& Cellular Life Sciences Journal}

17. Aye IL, Lager S, Ramirez VI, Gaccioli F, Dudley DJ, et al. (2014) Increased maternal body mass index is associated with systemic inflammation in the mother and the activation of distinct placental inflammatory pathways. Biol Reprod 90(6): 129.

18. Calabuig-Navarro V, Haghiac CM, Minium J, Glazebrook P, Ranasinghe GC, et al. (2017) Effect of maternal obesity on placental lipid metabolism. Endocrinology 158(8): 2543-2555.

19. Cetin I, Parisi F, Berti C, Mandò C, Desoye G (2012) Placental fatty acid transport in maternal obesity. J Dev Orig Health Dis 3(6): 409-414.

20. Gil-Sanchez A, Koletzco B, Larquè E (2012) Current understanding of placental fatty acid transport. Curr Opin Clin Nutrit Metab Care 15(3): 265-272.

21. Dubè E, Gravel A, Martin C, Desparois G, Moussa I, et al. (2012) Modulation of fatty acid transport and metabolism by obesity in the human full- term. Biol Reprod 87(1): 1-11.
22. Kim DW, Young SL, Grattan DR, Jasmin CL (2014) Obesity during pregnancy disrupts placental morphology,cell proliferation and inflammation in a sex-specific manner across gestation in the mouse. Biol Reprod 90(6): 130.

23. Castejón SOC, Canache CLA, Canache HSJ, Castejón SOA (2000) Mediciones materno-feto-placentarias según la edad de la gestación. Gac Med Caracas 108(4): 525-530.

24. Leal M, Giancomin L, Pacheco L (2008) Pre-gestation body mass index and maternal weight gain, its relationship with the newborn weight. Act Med Costarricence 50(3): 160-167.

25. Rasmussen KM, Yaktine AL (2009) Committee to reexamine IOM pregnancy Weight guidelines. Weight gain during pregnancy: Reexamining the guidelines. Washington (DC), National Academies Press (US). 